\title{
FILOSOFÍA PARA NIÑOS Y NIÑAS DESDE SUS NOVELAS
}

Alex Fabián Mejía S.

\section{Resumen}

El texto presenta una breve introducción acerca de lo que es la Filosofía para Niñas y Niños (FpNN) a partir de las mismas novelas base del programa desarrollado por Matthew Lipman y un grupo interdisciplinario que, desde finales de los años setenta, en la Universidad de Montclair, en Estados Unidos, proponen un sistema educativo que une la filosofía pragmatista de Jhon Dewey a la pedagogía de la liberación de Freire y al constructivismo de Piaget para lograr desarrollar en niños y jóvenes actitudes filosóficas como: pensar por uno mismo y el manejo de la investigación filosófica como elementos que facilitan su proceso de maduración ético, moral y cívico. Se presenta en este trabajo preguntas que indagan los conceptos de 'filosofía,' 'niña/o', 'pensar por sí mismo'; su tratamiento nos dará una imagen de lo que constituye la propuesta desde los mismos relatos del programa;

* Magister en Filosofía por la Pontificia Universidad Católica del Ecuador. Estudios en FpNN con Ann Sharp (USA), Eugenio Echeverría (México) y Diego Antonio Pineda (Colombia). alex_fabian@ hotmail.es 
también se comenta el rol del tutor y un breve estado de la situación de FpNN en Ecuador con una bibliografía mínima.

\section{Introducción}

El programa de Filosofía para Niños y Niñas tiene origen con la aparición y puesta en práctica en el aula de la novela Harry Sttotlemeier's, del profesor de Lógica, Matthew Lipman, quien había decidido abandonar la idea de enseñar a estudiantes universitarios porque, aparentemente era muy tarde para lograr que desarrollen habilidades propias de un razonar con sentido; su nuevo planteamiento consistía en que se debía comenzar con anterioridad el proceso de la enseñanza a pensar por sí mismo, por ello diseñó la novela con el objetivo de lograr contextualizar la enseñanza de la lógica formal a las edades de 10 y 11 años. Con esta experiencia y siguiendo los pasos del alemán Nelson, quien lo hizo con adultos, logró por una parte enfatizar el rol del pensamiento en la educación secundaria y primaria; y por otra, la dramatización novelística de la comunidad de investigación.

El número de novelas escritas por Lipman, y las edades a las que iban destinadas se amplió hasta llegar el programa a llamarse filosofía $3 / 18$, pues permitía trabajar en ese rango de edades. Las temáticas abordadas se han dividido según las más representativas partes de la filosofía; en el siguiente cuadro se recogen las más importantes:

\begin{tabular}{|c|l|l|}
\hline \multicolumn{3}{|c|}{ Programa de Filosofía para Niños y Niñas } \\
\hline Edad & \multicolumn{1}{|c|}{ Novela } & \multicolumn{1}{c|}{ Tópico filosófico } \\
\hline $3-5$ & Clínica de Muñecas & Ética \\
\hline $5-6$ & Elfie & Lenguaje \\
\hline
\end{tabular}




\begin{tabular}{|c|l|l|}
\hline \multicolumn{3}{|c|}{ Programa de Filosofía para Niños y Niñas } \\
\hline Edad & \multicolumn{1}{|c|}{ Novela } & \multicolumn{1}{c|}{ Tópico filosófico } \\
\hline $6-7$ & Pixie & Comunicación \\
\hline $7-8$ & Nous & Valores \\
\hline $9-10$ & Kyo y Gus & El conocimiento \\
\hline $11-12$ & Harry & Lógica \\
\hline $13-14$ & Lisa & Ética \\
\hline $15-16$ & Suky & Estética \\
\hline $16-17$ & Mark & Política \\
\hline $17-18$ & Harry Prime & Investigación filosófica \\
\hline
\end{tabular}

* Su autora es Ann Sharp, estrecha colaboradora de Lipman.

Para entender cómo funciona el programa se presentarán sus principales características a partir de las novelas mismas.

\title{
¿Qué es filosofía para niñas y niños?
}

\author{
Es una contribución \\ a la liberación cognitiva del niño. \\ Matthew Lipman
}

Trataré de exponer en este apartado lo qué supone el programa cuando dice que esta haciendo filosofía, y no otra disciplina o actitud.

Lo que se puede observar en las novelas del programa es "la provocación constante a la reflexión" por tratar de ir más allá de un simple pensamiento; por ejemplo, en la novela Kyo y Gus, se inicia con la pregunta: “QQuieres saber de verdad lo que hice las últimas vacaciones?"1. Una pregunta a simple vista cotidiana y sin mayor interés; pero, la cursiva en la palabra 'verdad', puesta a propósito por el programa, ya sugiere que existen otras maneras de 'que- 
rer saber', pero eso es angustiante, es decir, ¿puede alguien querer saber de mentira-s algo? En principio, el sentido común me dice que no, pero se pudiera pensar que existen casos en los que se justificaría una mentira; por ejemplo, el caso en el que el médico decide mentirle a su paciente con una enfermedad terminal acerca del estado verdadero de su salud; o el 'verdadero' criterio sobre una pintura de un principiante visto por su maestro; tanto el paciente como el principiante demandan querer saber de verdad, en realidad no es difícil imaginar que hay casos en que quisieran que se les mienta.

Además, hay que notar que la frase nos llevó a discutir sobre un tema que no tiene nada que ver con el contenido sobre las vacaciones del personaje que realizó la pregunta; es un tema -por decirlo de alguna manera- muy general el que se ha provocado y asombrosamente impactante para un posible lector: ¿Puede alguien querer conocer algo de 'mentiras'? No me queda sino recordar los diálogos platónicos cuando se discute sobre los significados posibles para la palabra sōphrosynē, que puede entenderse como mesura o sensatez. Seguramente es por lo que se plantea como filosófica la novela, o la actitud o las posibles reacciones a las que nos lleva la provocación muy mal intensionada, es decir, sin ingenuidad, que pretende poner una trampa al lector para que al leer o conversar las narraciones se termine en un diálogo como el que mantuvieron los griegos (seguramente idealizados también) hace más de dos siglos.

En otras novelas, son los mismos personajes que se asombran con descubrimientos, como Harry al darse cuenta que en las oraciones que comienzan con la palabra 'todos' no son posibles de mutar su sujeto por su predicado sin cambiar el sentido de la oración, y que en las oraciones que comienzan con la palabra 'ninguno', este cambio sí era posible hacerlo sin que afecte su significado. Quizá en estos casos la narración se nota forzada para lo- 
grar este tipo de análisis filosófico, mas este es el ideal de pensador que desea llegar a tener el programa. El asombro de Harry está acompañado por una alegría al lograr poner en práctica dicho saber al corregir a su vecina: "solo porque, según usted, 'todos los que no pueden dejar de tomar son personas que van a la cantina, todos los que van a la cantina', no tienen porque 'ser personas que no pueden dejar de tomar'”. Así, la concepción de una filosofía que piensa elementos formales y muy generales como en el caso anterior, se complementa con un filosofar que en cierta practicidad corrige el pensamiento, procurando que el mundo en el que vivimos sea mejor.

Un elemento adicional que se observa en las novelas es que la filosofía "es un proceso lúdico", no es un pensar por pensar, constantemente las adivinanzas, los juegos de palabras, retos y astutas actividades convierten a las novelas en un juego sin fin; nada es tan motivador para una mente despierta como la de la niña y el niño que el juego. Por ejemplo, la novela Pixie se desarrolla completamente en la construcción -solicitada por su profesora- de una criatura que pudiera encontrarse en la salida al zoológico que está preparando con sus estudiantes. Todo este desarrollo, ya lúdico, está salpicado de varias motivaciones como cuando le pide Pixie a su papá que le siembre nuevos dientes porque los de leche se le han empezado a caer; al igual que las plantas, ella le solicita a su padre que siembre en su boca nuevos dientes.

Como síntesis, filosofar para el programa es el camino lúdico que va de lo cotidiano a la reflexión abstracta y de ella un regreso a la practicidad en la que se gana justicia, belleza, verdad o bondad, y que lejos de ser el fin de la filosofía nos permite diseñar un mundo mejor a partir de las ideas de las y los niños. Este proceso se muestra en el siguiente diagrama del filosofar. 


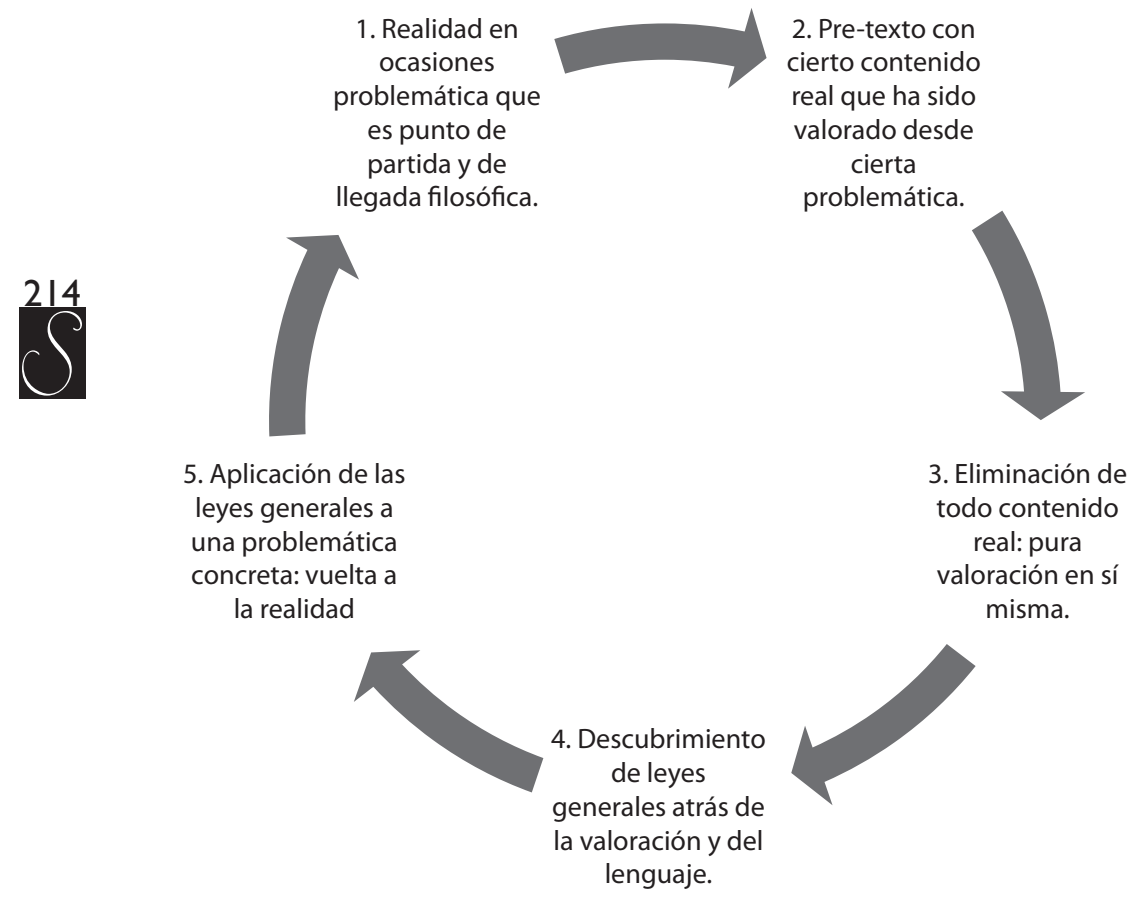

Figura 1

Diagrama de las etapas del filosofar propuesto en FpNN.

Pasemos a continuación a descubrir el tipo o estereo-tipo de niño o de niña que maneja el programa para responder a la demanda del filosofar desde los propios contextos en que se desenvuelve. 


\section{La preconcepción filosófica de 'niña/o'}

Después de todo, los niños constituyen una gran parte de la población del mundo y aunque cada niño es patéticamente débil, los niños nos tocan con sus, a menudo, heróicos esfuerzos para ser fuertes y razonables en un mundo que no sabe ser fuerte y razonable con ellos, a cambio.

Matthew Lipman

En el programa de FpNN, la concepción de 'niña'o 'niño' en las novelas está enfatizada primero en cuanto a la actitud, no se refiere solamente a los individuos de corta edad sino a los que se admiran por situaciones de la realidad, de las ideas o de las relaciones con otras personas; segundo, efectivamente a los de corta edad como seres privilegiados para la discusión filosófica ya sea por una inteligencia rápida, fresca, pero también profunda y de largo alcance; tercero, no son niños comunes, se plantean como modelos a seguir por los que leen las novelas y ven en los comportamientos un ejemplo de respeto, criticidad y de creatividad; cuarto, las características muy especiales de los niños, ya sea por su carácter, o por sus características especiales, ya sean físicas o familiares.

Para el primer caso vemos que, por ejemplo, los padres o maestros son los que filosofan con radicalidad, pero también se les puede considerar como niños ya que no son adultos comunes y corrientes; tienen la disciplina propia de un adulto, pero la alegría y motivación a pensar por sí mismos de un niño, se pudiera decir que son niños que se encuentran atrapados en cuerpos de adultos. El mecanismo con el que realizan su papel los adultos en las novelas no es a través de posiciones o sentencias 'inteligentes', sino de preguntas y "cuestionamientos que permiten un 
diálogo" normalmente muy interesante, veamos la conversación entre Harry y su padre narrada en la novela Marco:

- El otro día en clase — continuó Harry— se planteó el problema de si la historia se repite o no. Algunos querían que votáramos para decidir si se repetía o no; ¿te lo puedes imaginar?

- ¿Quieres decir que hay determinados problemas que es absurdo intentar resolver mediante el voto de la mayoría? - dijo su padre.

- Claro, en el caso del saber si la historia se repite, no hay prisas para saberlo - exclamó Harry, algo acalorado- $\mathrm{Y}$ en todo caso, ¿Qué probaría el voto?

— Pero algunas veces, — dijo su padre lentamente- es necesario tomar una decisión, porque se debe emprender alguna acción, incluso aunque no se disponga de la evidencia necesaria.

En este pequeño diálogo se puede observar la actitud de admiración de Harry frente a la posibilidad de resolver problemas por medio de una votación; por una parte se puede ver que no acepta la falacia de los números grandes, la simple mayoría no puede ser una buena razón en ciertas circunstancias, pero el padre hace de abogado del diablo para indicar que en ciertos casos es una salida práctica. Como es de imaginar la discusión no tiene un final; pero es en sí ya muy interesante el modelo de 'niño' que se descubre en los adultos. Veamos otros extractos de la conversación de Harry con su padre, esta vez de la novela Lisa:

—Papá —dijo Harry.

- Mmmmmmmm — dijo su padre.

-Papá, ¿qué es una pregunta?

—Lo que tú me estás haciendo (...). 
-Papá, ¿qué crees tú? ¿Está bien que las personas comamos animales?

- Solo si están cocinados, crudos no son muy buenos que digamos.

-Vamos, papá. Mis compañeros estuvieron hoy hablando del tema en el colegio. ¿No sería mejor que todo el mundo dejara de comer carne?

- ¿Pero qué pasa? ¿Hay escasez de carne?

—No, pero quizás esté mal matar animales solo para comérnoslos.

- Si quieres que la gente deje de comer pescado y carne, más vale que te asegures de que hay otro tipo de alimentos disponibles para ellos.

—Eso es fácil. Cultivar más granos y verduras.

- Más fácil es decirlo que hacerlo.

— Tal vez haya demasiada gente — nada más decir esto, se sintió incómodo. Recordó la observación de Raúl acerca de la necesidad de matar tórtolas porque había demasiadas. Harry sacudió la cabeza-.

No entiendo. Hay que tener en cuenta demasiadas cosas.

—Bien — replicó su padre-, pero tú quieres ver el cuadro completo, ¿no? Siendo así, tienes que tener todo en cuenta.

- ¿Todo?

- Por supuesto, una de dos: o crees que está bien matar animales y comérselos, o crees que no. Tienes que considerar todas las eventualidades: lo que pasa si nos los comemos, y lo que pasa si no nos los comemos.

—Entonces, ¿qué deberíamos hacer?

El señor Dayer abrió el periódico y dijo:

- ¿No dirías que lo que tenemos que hacer depende en gran manera de la clase de mundo en que queremos vivir? 
- Supongo que sí.

-Entonces esa es mi respuesta. Algo puede parecer mal hecho, pero luego, si tienes todo en cuenta, puede parecer bien. O justo al contrario: primero puede parecer bien y luego mal, considerando el conjunto.

Para el segundo caso, la actitud filosófica es mucho más clara, son los niños cronológicos los que representan a los filósofos por excelencia, sobre todo, con el papel que ha dado el autor a las preguntas; cuando Pixie descubrió que su pie se había quedado dormido pensó que era el pie de su hermana, entonces le pregunta, ¿Crees que si mi cabeza se queda dormida, pensaré que es la tuya? O cuando Jerónimo hace cara de asco al enterarse que van a salir al Zoológico y le dice: "Jerónimo, ¡te crees muy listo!, ¿no? ¿Cómo crees que olerías tú si tuvieras que pasarte encerrado en una jaula?". En el primer caso la pregunta apunta al concepto de identidad, en el segundo al de solidaridad, en los dos casos está el ponerse en el lugar del otro.

Los niños son modelos para los lectores es el tercer caso, normalmente los modelos de los niños y niñas son adultos, incluso la pregunta de qué quieres ser cuando seas 'grande' supone una no-existencia presente, una ontología en potencia que vacía de sentido la niñez. En las novelas son admirables y sorprendentes los niños y no porque dejen de serlo, no tienen que parecer adultos o comportarse como hombrecitos o mujercitas para ser valorados, de hecho siguen siendo lo que son y en su niñez desarrollan las habilidades del pensamiento filosófico. En Clínica de Muñecas, en una discusión sobre las muñecas Daniela participa diciendo: "Cuando piensas en una persona que te cae muy bien, ¿no piensas que es muy bonita?" y Dora se dice a sí misma: "Me gusta cuando habla Daniela". De igual manera en la novela Lisa, aunque cada personaje es 
muy diferente, son modelo ya sea por su facilidad para "encontrar alternativas" frente al tema que se plantea, o por la "fuerza lógica" de sus participaciones, o por la "solidaridad que expresan sus ideas" o sus actos, cada personaje encarna un ideal de comportamiento para los que trabajamos con las novelas. Reproduzco a continuación un diálogo entre ellos al discutir sobre si tienen o no derechos los animales:

— ¡Eh, Francisca, ¿tú que crees?, ¿tienen derechos los animales? — dijo Lisa.

— Tú me estás tomando el pelo —rió Francisca-. Algunos no quieren admitir ni que las personas tenemos derechos, así que quién admitiría que los animales los tienen. Además, puedo imaginarme algún día de abogada en los tribunales defendiendo a un gato al que le han pisado la cola.

- ¿Y qué piensas de los niños? —añadió Marco-. ¿Tienen derechos?

— ¡Los niños! —rió Francisca de nuevo-. Están a medio camino entre las personas y los animales. Así es como piensan algunos.

- Los niños adquieren derechos cuando crecen -comentó Bernardo Bejarano.

— ¡Qué va! — dijo Marco-. Uno tiene derechos desde el momento en que nace. Tienes derecho a ser alimentado y vestido. Tienes derecho a la salud y a la educación. Tienes un montón de derechos desde que eres un chiquillo.

— Pero, ¿y los animales? —insistió Lisa-. ¿Tienen derecho a que no los maten y se los coman?

- Ellos tienen derecho a matarnos y comernos si nos atrapan — contestó Bernardo-, y nosotros tenemos derecho a matarlos y comerlos a ellos si los atrapamos. 
- ¿Es lo mismo respecto de las personas? —Preguntó Harry - ¿Es precisamente el ser capaz de capturarlos lo que nos da derecho a matarlos?

- Por supuesto - contestó Bernardo-. Y cuando esto ocurre lo llamamos guerra y eso está permitido.

Para el cuarto caso quisiera mencionar por un lado el caso especial de los mismos niños, en la novela Kyo $y$ Gus; a los lectores nos sorprende enormemente que ya avanzada la novela descubramos que Gus es no-vidente, y podamos entender las frases y las acciones que Gus realizó con anterioridad; nos sorprende que no hayamos podido deducirlo antes, desde allí en adelante la novela es otra, comprendemos claramente entonces cuando realizan una pequeña actividad con barro:

Kio— digo-, mi papá y mi mamá me han conseguido arcilla de verdad. Yo he hecho ya un gato. ¿Quieres probar?

-Por supuesto- dice Kio.

Lo llevo a mi habitación y le doy un poco de arcilla. - Haz algo- digo.

— ¿Qué podría hacer? - dice él — ¡Ya sé!, ¡haré un durazno! - Da vueltas un poco de arcilla entre sus manos hasta que tiene una pelota redonda, después me la da a mí- ¡Ahí tienes! — dice— Un durazno. -Eso es una tontería — contesto- Mira, déjame enseñarte. - Cojo un trozo de arcilla y lo convierto en una pequeña bola.

—Esa es la pepa — digo.

Después añado más arcilla alrededor.

-Esa es la pulpa - digo.

Y después lo recubro todo con otra capa de arcilla.

—Todo lo que yo veo es la piel— dice Kio. 
—Cierto, quizá sea eso todo lo que tú ves- digo yo-, pero tú sabes que lo que yo hice es realmente un durazno y lo tuyo no. Lo mío es un durazno con todas sus partes.

Kio no contesta durante un momento. Después me pasa un poco de arcilla y dice:

Haz una cabeza.

Así lo hago y se lo explico mientras trabajo:

-Mira, primero hago el interior de la garganta y la boca. Luego, pongo la lengua dentro. Después añado los dientes, todo alrededor de las encías. Luego pongo los labios por encima de los dientes. Después cubro la cabeza, saco la nariz del interior y hago los ojos con mis uñas. Luego añado el pelo y ahí está.

-Yo empiezo desde el exterior y tú desde el interior-dice.

— ¡Nunca te metes dentro! — contesto- ¡Sólo te quedas fuera! ¡Esa no es forma de hacer una cabeza! -Es la única forma que conozco- dice Kio.

-Era la única forma que conocías- contesto - ahora conoces dos modos.

En los relatos del programa nos encontramos constantemente con niños que viven solo con su madre porque se ha divorciado, o con solo su padre porque ha fallecido su madre; además con situaciones conflictivas por la violencia de los barrios o por las situaciones que enfrentan como el espendio de drogas en los colegios; en definitiva, los relatos han idealizado a los personajes como "pensadores competentes, pero no los han desubicado de las situaciones reales" que viven tanto los niños como los jóvenes hoy en día, para quienes su mayor lucha es la de creación de sentido frente a un mundo que se asume y al 
mismo tiempo busca mejorar. Veamos un diálogo de Millie con su abuelo que se encuentra en la novela Lisa:

—Abuelo — preguntó, un poquito más alto y menos indiferente de lo que hubiera querido—, ¿dónde..., dónde está la abuela?

Como su abuelo no contestó inmediatamente, Millie no pudo evitar adelantarse diciendo: — ¿Murió? El abuelo de Millie pareció sorprendido.

—Creí que lo sabías —exclamó-. Creí que tus padres te lo habían contado.

- ¿Contarme qué?

-Que tu abuela y yo nos habíamos divorciado. ¿Divorciado? Esa posibilidad nunca se le había ocurrido a Millie. Pero ahora se creyó con derecho a una explicación.

—Bien —empezó su abuelo, golpeando la pipa contra la palma de la mano más enérgicamente que de costumbre-, nunca pasábamos mucho tiempo juntos. Yo siempre estaba fuera, en los bosques o en las montañas, así que ella tenía que hacer su propia vida. Ambos estuvimos de acuerdo en lo del divorcio; de hecho, seguimos siendo buenos amigos.

— ¿Pero dónde está ella ahora?; ¿qué hace? El abuelo sonrió para sí.

— ¡Oh, le va bien!, según tengo entendido. Se ha vuelto a casar.

- ¿No es demasiado mayor para volverse casar?

— ¿Qué va!, ¿por qué dices eso? Tiene cincuenta y pico, como yo.

—Bueno —insistió Millie-, ¿y eso no es ser muy "viejo"? Su abuelo rió.

- Me doy cuenta de que no recuerdas a tu abuela. ¿Ella demasiado vieja? ¡Ella nunca será demasiado 
vieja! - - luego añadió con una curiosa nota de orgullo-, de hecho se ha casado con un hombre diez años más joven que ella.

Millie se quedó confundida. Se le ocurrieron más preguntas que no pudo formular.

El diálogo con su abuela le lleva a Millie a replantearse varias cuestiones que aparentemente las tenía asumidas sin mayor dificultad. Millie buscará con su amiga Lisa conversar lo que se ha enterado y que ahora la perturba, luego de contarle Lisa le responde:

-Ummmmmm — dijo Lisa-. Diría que lo que tu abuelo debe hacer ahora es buscar una guapa viuda de 40 años.

Millie sacudió la cabeza. La idea de que su abuelo se volviera a casar le parecía inapropiada por completo:

- ¿Qué te gustaría que hiciera, que pasara el resto de su vida solo? — preguntó Lisa.

Millie quiso saber qué habría de malo en ello.

—Bien, mira tu abuela. Él podría estar casado y feliz, como ella. Millie se estremeció.

- ¿Cómo puedes hablar así? Está mal, pero que muy mal que se haya casado con un hombre al que lleva tantos años. Lisa frunció los labios.

— ¿Está mal que un hombre se case con una mujer más joven que él?

- Por supuesto que no.

— ¿Entonces por qué está mal que una mujer se case con un hombre más joven?

—Porque está mal, por eso — dijo Millie. Lisa sacudió la cabeza.

-No entiendo. Si está bien en un sentido debería estarlo en el otro. Realmente no lo entiendo. 
Para resumir la preconcepción del niño y la niña del programa podemos entonces decir que se observan niños y niñas que manejan el arte de preguntar, indagar y ponerse en lugar de otra persona para cambiar su forma de ver el mundo, un apropiarse con sentido del mismo y procurar integrar en esa apropiación a los que aparentemente son distintos tanto cultural como ideológicamente. Claro que no deja de ser forzada la figura de los personajes, pero definnitivamente es lo que en el aula pretende equilibrar el desinterés generalizado en que nos encontramos.

\section{Pensar por sí mismo}

¡Sapere aude! ¡Ten valor de servirte de tu propio entendimiento!

Kant

Para conntinuar con esta muestra de lo que es FpNN, se puede encontrar en las novelas un deseo constante a responder al pedido de Kant, en su escrito “ ¿Qué es la ilustración?" a pensar por nosotros mismos para llegar a un verdadera desarrollo como individuos. Kant dice:

Oigo exclamar por doquier: „no razones! El oficial dice: ¡no razones, adiéstrate! El financista: ¡no razones y paga! El pastor: ¡no razones, ten fe! Por todos lados, pues, encontramos limitaciones de la libertad. Pero ¿cuál de ellas impide la ilustración y cuáles, por el contrario, la fomentan? He aquí mi respuesta: el uso público de la razón siempre debe ser libre.

En todas las novelas se provoca, se insiste, se empuja a que sus personajes y el lector corrijan el defecto de 
la dependecia en la esfera de las ideas. Una idea para ser respetada, debe ser sobre todo 'propia', no necesariamente original, pero sí propia, es decir que la hemos desarrollado por nosotros mismos. Miremos el final de un bello diálogo que tiene Pixie acerca del tiempo y el espacio:

—El tiempo! —grité-. Eso es como el espacio, solo una palabra.

—Mira, Pixie — me dijo Miranda-. Es tarde y la escuela está muy lejos. Cuando hablamos del tiempo queremos decir más temprano y más tarde. Cuando hablamos del espacio queremos decir lejos y cerca. ¿Entiendes?

Fue como si una luz se hubiera encendido en mi cabeza.

— ¡Ah! — dije- —. Ahora entiendo lo que me quieres decir. Ahora entiendo de qué están hechos el espacio y el tiempo. El espacio está hecho de relaciones espaciales y el tiempo está hecho de relaciones temporales. ¿Es eso lo que quieres decir?

"Como si una luz se hubiera encendido en mi cabeza", esa experiencia se repite constantemente; no son procesos fáciles, muchas ocasiones se aprecia que el entendimiento está limitado también por las emociones y las creencias que fueron trasmitidas por la familia, religión o incluso en la propia escuela. Superar esas creencias y lograr reafirmarlas, modificarlas o cambiarlas completamente permite al niño y a la niña crear un mundo pleno de sentido. En las novelas, no es tan problemático lo que se dice en sí mismo; sino el cómo se llegó a esos conocimientos o a como se los transmite. La pregunta ¿cómo tú sabes? es central y no se aceptan salidas simples o falaces para defender las opiniones en juego. Miraremos un ejemplo de las novelas en el siguiente apartado que nos muestra también el rol del tutor. 


\section{Creando lugares seguros del pensamiento, el rol del tutor}

Adoro las preguntas que me hacen discutir.

Nielsen, 10 años.

El programa de FpNN tiene como uno de sus objetivos primordiales la creación de espacios seguros para la indagación filosófica, y ese es el papel del tutor en la clase. Un espacio seguro incluye, como se puede ver en las diferentes novelas, normas de comportamiento que si bien se pueden poner a discusión, una vez concensuadas tienen que ser respetadas por el grupo. La libertad que se proclama en FpNN no es física, es una libertad de pensamiento, y por ello si no se logra crear un espacio de elevado respeto, difícilmente podremos mantener un ambiente de diálogo seguro para los que participan. Dicha seguridad incluye también ciertos hábitos de comunicación y corrección lógica. Miremos como se presenta un diálogo facilitado por la profesora Myriam Jaimes en la novela Harry, el grupo quiere discutir sobre la negativa a ponerse de pie para el saludo a la bandera y permite que en su clase se dé el diálogo:

Había tanta algarabía que la profesora Myriam Jaimes tuvo que dar cuatro golpes en su escritorio hasta que el curso se calmó. Toño tenía la mano levantada. — ¿Qué pasa, Toño?

-Myriam — dijo Toño, muchos de nosotros tenemos opiniones sobre lo de Daniel. ¿Podríamos hacer un debate sobre esto en vez de una clase normal?

- Tenemos una lección por acabar y debemos seguir con ella, pero solo por hoy está bien, ¿quién quiere hablar primero? 
Manuela Vargas intervino: - Creo que Daniel debería ponerse de pie durante el saludo, como todos.

—iPor qué? — preguntó la señorita Jaimes.

Manuela levantó la vista y declaró: - Bueno, no tengo ninguna razón. Solo sé cómo lo siento.

-Bien, entonces, cuando hayas averiguado por qué lo sientes así, hablamos. ¿Quién sigue?

—Yo sé por qué — dijo Guillermo. El país está desmoralizado. Están sucediendo toda clase de desórdenes. Es como un barril de pólvora: una pequeña chispa y todo puede estallar. Por eso, no creo que podamos permitir que la gente vaya por ahí haciendo lo que le dé la gana.

La señorita Jaimes contestó: - Guillermo, tú no tratas de convencernos. Tú tratas de asustarnos para que estemos de acuerdo contigo. 1ro. dices que estás alarmado por la situación, y que, por lo tanto, habría que obligar a Daniel a ponerse de pie. Pero de lo uno no se sigue lo otro. No has demostrado que todo estallará si Daniel no se pone de pie durante el saludo...

Y Janeth interrumpió: - Creo que Daniel debe ser fiel a sus creencias porque eso dice mi hermano.

- ¿Es tu hermano abogado o juez o una autoridad de algún tipo? — preguntó la señorita Jaimes.

—No, pero es muy inteligente — replicó Janeth.

-Bueno, lo siento pero no sirve. Solo deberías utilizar la opinión de otra persona en favor de tu propio modo de ver si esa otra persona tiene buenos argumentos sobre el tema en cuestión.

Susy Ramírez dijo que habría que obligar a Daniel a ponerse de pie, pues las reglas son las reglas.

La señorita Jaimes dijo: - Una afirmación como las reglas son las reglas es como decir las piedras son las piedras. Pero, a veces, se trata de frases hechas 
con un sentido concreto que todos entienden, como "el negocio es el negocio". En este caso, supongo que quieres decir que, si tenemos reglas, tenemos que respetarlas. De modo que vale.

Ahora Miguel tenía la mano levantada: - No —insistió-, las reglas se hacen para romperlas. ¿No conoce el dicho "la excepción confirma la regla"? Bueno, ¡pues el caso de Daniel es la excepción! Por eso creo que Daniel no tiene que ponerse de pie si no lo desea. La señorita Jaimes indicó: —De acuerdo, Miguel, creo que si he dejado que Susy diera como razón una frase hecha, tendré que dejarte a ti hacer lo mismo. Pero aún así creo que en lugar de darme una razón me has dado una excusa bastante pobre.

Toño metió cuchara... - Myriam, puede que Miguel no lo haya dicho bien, pero no creo que lo que ha expresado esté tan mal como usted dice. Muchas veces sabemos que hay excepciones, pero aun así hablamos como si no las hubiera. Por ejemplo, dices "la madera flota”, aunque sabes que el ébano no flota.

La Srta. Jaimes intervino enseguida: —estamos apartándonos del tema. ¿Quién quiere hablar ahora? Santiago Mendoza sintió la necesidad de indicar:ç - Creo que estamos olvidando que no elegimos ir al colegio: nos hacen ir al colegio. Ni elegimos la religión que tenemos: nos la imponen al nacer.

— ¿Qué quieres demostrar con eso? — preguntó la señorita Jaimes.

Santiago se encogió de hombros:-No lo puedo decir mejor que como lo he dicho.

Entonces intervino Toño: - Creo que quiere decir que si perteneces a un grupo, como una banda, entonces tienes que hacer todo lo que te digan. Pero, si eres miembro de un grupo al que no has elegido pertenecer, no deberían presionarte a hacer cosas 
contra tu voluntad, como Daniel no escogió pertenecer a su religión, no tiene por qué hacer lo que ella le ordena si piensa que no está bien hacerlo.

A Juanita se le ocurrió: - ¿Y eso también se aplica a las familias? Después de todo, no elegimos a nuestros papás.

- Creo — dijo Ma. Fernanda- que viene a ser una cuestión de confianza. Yo confío en mi familia. Tú no los elegiste, pero ellos te eligieron a ti, y sabes que te quieren. Con los extraños la cosa es diferente.

—Sin duda — replicó Santiago_- pero entonces son como en la pandilla; haces lo que quieren porque quieres seguir formando parte de la familia.

La Srta. Jaimes comentó: - Nunca lo había pensado de esa manera. Muchas gracias a todos.

Como se observa, este modelo de tutora está pendiente de crear un lugar seguro, no solo en la disciplina que es básica, sino también en el rigor lógico, en la corrección de razones que no se puedan calificar de 'buenas razones', todo ello sin establecer cosas dando 'las respuestas'. Los tutores buscan inquietar pero al mismo tiempo encaminar el diálogo para que no se estanque, "se respeta la racionalidad, pero prefiere la razonabilidad", lo cual le da al programa un componente político que refiere a la democracia como el camino, no ideal, pero el mejor que tenemos para entablar diálogos entre diferentes que no quieren, ni es deseable que lo hagan, ser iguales. Mientras la filosofía permita enriquecer las aulas con diálogos y discusiones creadoras de sentido, el futuro de la democracia contará con el aseguramiento de su universalidad y la fuerza que determine las acciones estará planteada en 'buenas razones' y no en estrategias mediáticas que niegan a los otros como individuos y que buscan en las diferencias los pretex- 
tos para las separaciones en lugar de la fuerza misma de la unión solidaria de la humanidad.

Para ver un esquema básico del diálogo presentado en las novelas y que tendrá que reproducir el tutor en las aulas tenemos:

- Lograr un acuerdo de normas para el diálogo como levantar la mano o levantar su turno.

- Compartir un segmento de la realidad que pudiera ser problemática y que servirá de pretexto para provocar el diálogo (en el aula suele ser la misma novela).

- Abrir el diálogo por medio de la recolección de opiniones y preguntas relacionadas con la problemática expuesta.

- Elegir o concentrar el diálogo en una de las opiniones o preguntas expuestas que haya causado impacto en el grupo.

- Mantener la motivación por la discusión, a través de preguntas o moderamiento de opiniones en aspectos de corrección lógica, creativa o solidaria entre los dialogantes.

- Clausura de diálogo que no quiere decir del tema, o que necesariamente ha llegado a una respuesta o posición grupal.

Como se aprecia, el rol del tutor es clave e implica varias habilidades que se ejemplifican constantemente en las novelas deberán ensayar los tutores.

\section{Estado de $\mathrm{F}_{\mathrm{pNN}}$ en Ecuador}

- ¿Puedo hacer una pregunta? Si la mente sabe cómo funciona el corazón, entonces ¿por qué no puede hacer que deje de latir? (Se levantan algunas manos). 
-Es que tú entendiste mal. Lo que la mente hace es pensar cómo funciona el corazón, pero el cerebro es el que le hace funcionar. (Interrumpiendo y con cierto dejo irónico)

-Pero el que le hace funcionar debe saber cómo hacerlo funcionar... - ¿Estás diciendo que el cerebro es lo mismo que la mente? -Sí, ¿o crees que hay una mente que funciona sin el cerebro?

Diálogo de un grupo de 9 años en Quito ${ }^{4}$.

El programa de FpNN en Ecuador se ha dado por varias iniciativas más bien sueltas, y en ciertos casos lo que se ha realizado es la formación de docentes para la aplicación del mismo, tanto en educación formal en el Instituto Nacional del Niño y la Familia (INNFA), la Pontificia Universidad Católica del Ecuador-Quito (PUCE-Q) como en educación informal en el Centro Ecuatoriano de Capacitación y Formación de Educadores de la Calle (CECAFEC) se han preparado varios grupos quienes han logrado llevar el programa a niñas y niños de varias escuelas y guarderías; como también a jóvenes de colegios y de programas como el del muchacho trabajador. En varios colegios tras varios años de realizar el programa de manera institucional, lo redujeron a una herramienta del docente dentro de ciertas materias que son afines al diálogo y a la reflexión.

Es relevante en este desarrollo indicar que la primera institución que realizó FpNN en Ecuador fue la Academia Cotopaxi en los años ochenta; la formación nacional que realizó el INNFA, el Congreso Internacional desarrollado por el Colegio Liceo Internacional en el 2001 y los cursos abiertos que ofrece la PUCE-Q para la formación de docentes interesados en aplicar el programa. La tarea 
pendiente es la de conformar un Centro de Filosofía para Niños en Ecuador ${ }^{5}$, centro que deberá tener como misión la de formar docentes, asesorar instituciones educativas, publicar los materiales adaptados al contexto ecuatoriano y la de liderar la investigación pedagógica del desarrollo de las habilidades del pensamiento en el Ecuador.

\section{Bibliografía básica}

\section{Textos}

Kohan, Walter y Vera Waksman (compiladores)

2000 Filosofía para Niños. Discusiones y propuestas, Buenos Aires: Novedades Educativas.

Kohan, Walter y Vera Waksman

2000 Filosofía para niños. Aportes para el trabajo en clase. Buenos Aires: Novedades Educativas.

Lipman, M.

1993 La filosofía en el aula, trad. García Morrión y otros, Madrid: De la Torre.

1997 Pensamiento complejo y educación, trad. V. Ferrer, Madrid: De la Torre.

2006 El descubrimiento de Harry Stottlemeier, (n.e.) Quito: Efímera.

2006 Elfie, (n.e) Quito: Efímera.

2006 Pixie, (n.e.) Quito: Efímera.

2006 Kyo y Gus, (n.e.) Quito: Efímera.

2006 Suky, (n.e.) Quito: Efímera.

2006 Lisa, (n.e.) Quito: Efímera.

2006 Marco, (n.e.) Quito: Efímera.

2004 Nous., Madrid: Ediciones De la Torre.

Lipman, M. y A. Sharp

1978 Investigación Filosófica, Madrid: De la Torre.

1998 Investigación Ética, Madrid: De la Torre.

1990 Investigación Social, Madrid: De la Torre.

1993 Asombrándose ante el mundo, Madrid: De la Torre.

2000 Escribir Cómo y Por qué, Madrid: De la Torre.

Sharp, Ann

2006 Clínica de Muñecas, (n.e.) Quito: Efímera. 
Splitter, L. y A. Sharp

2001 La otra educación. Filosofía para niños y la comunidad de indagación, trad. S. Abad y otros, Quito, Editores Nacionales ${ }^{3}$.

\section{Referencias electrónicas}

Tomado de: 〈http://www.oocities.org/avcordero/FpN37.htm〉.

Tomado de: 〈http://www.crearmundos.net/pdfsrevista7/3d.pdf〉.

\section{Notas}

1 No se citarán las novelas para no molestar la lectura del artículo y porque corresponden las citas a las novelas adaptadas para Ecuador, y que no han sido publicadas. Su reproducción ha sido limitada para el uso de escuelas y colegios que ejecutan el programa.

2 La sala de lectura de la Escuela de Filosofía en la PUCE-Q ofrece un fondo bibliográfico sobre el tema.

3 Para ver una referencia mucho más completa, ver: 〈http://www.crearmundos.net/pdfsrevista7/3d.pdf).

4 Tomado de: 〈http://www.oocities.org/avcordero/FpN37.htm〉.

5 Han existido varios intentos pero ninguno ha logrado sostenerse como centro educativo en firme. 